\title{
PERSEU E MEDUSA: OS ENFRENTAMENTOS DAS PRÁTICAS ESCOLARES DE LETRAMENTO DIGITAL DO PROFESSOR
}

\author{
SILVA, Wellington de Brito ${ }^{1}$ \\ CASTRO, Paula Almeida de ${ }^{2}$
}

\begin{abstract}
RESUMO
O artigo apresenta como objeto de estudo a partir dos estudos etnográficos a discussão sobre a prática docente intermediada pelas tecnologias digitais. A analogia feita a Perseu e Medusa nos remete aos enfrentamentos diários do professor para estabelecer com as tecnologias da informação e comunicação elaborações mais orientadas com as demandas não apenas dos alunos, mas as próprias. A pesquisa realizada com sujeitos - alunos e professores - de uma escola pública de Educação Básica do município de São Bento do Una (PE) disponibiliza recursos digitais (lousas, equipamentos de informática, dentre outros em perfeito) para o uso em sala de aula. O estudo buscou analisar e apresentar a perspectiva do professor - sujeito da pesquisa sobre os usos das tecnologias disponibilizadas pelas escolas e a apropriação dos mesmos para a elaboração das aulas Verificou-se o impacto das mídias nos processos de ensino e aprendizagem e a necessidade de uma provocação para que os docentes desfaçam os mitos e busquem nas tecnologias os caminhos para a melhoria da qualidade do ensino.
\end{abstract}

PaLAVRAS-chaVE: Tecnologia - Ensino-aprendizagem - Educação Básica.

\begin{abstract}
The aim of this article is to present the study based on the ethnographic studies the discussion about the teaching practice mediated by digital technologies. The analogy made of mythology of Perseus and Medusa is to reminds us of the daily confrontations of the teacher in establishing connections with information and communication technologies elaborated with the demands not only of the students, but the own ones work at classrooms. The research carried out with subjects - students and teachers - of a public school (Basic Education) in the municipality of São Bento do Una (PE) that provides digital resources (slates, computer equipment, among others in perfect condition) for use in the classroom for teachers and students. The study sought to analyze and present the perspective of the teacher - subject of the research - on the uses of the technologies made available by the school and the ap-

\footnotetext{
${ }^{1}$ Doutorando pelo Programa de Pós-graduação em Educação da UFCE. Email: wbs_01@oi.com.br

2 Professora do Centro de Educação da UEPB. Email: paulaalcastro@terra.com.br
} 
propriation of the same for the elaboration of the classes. The impact of the media in the teaching and learning processes and the need for a challenge for teachers to undo the myths and seek in technology the ways to improve the quality of teaching.

KeYwORDS: Technology - Teaching-learning - Basic Education.

\section{INTRODUÇÃO}

$\mathrm{Na}$ atualidade vivemos um momento de rápidas mudanças que ainda não estão totalmente compreendidas. Nessas circunstâncias o sentimento de insegurança e incerteza nos conduz a lidar com os nossos medos e inevitavelmente nos faz encarar questões que às vezes preferimos deixar de lado ou, simplesmente, ignorar. Para começar essa reflexão, lembremonos do mito de Perseu e a Medusa. Por vezes os mitos nos ajudam a entender 0 mundo de uma maneira muito peculiar. Conta o mito que todos os que tentaram matar a medusa, ao olhar nos seus olhos, eram petrificados. Para derrotá-la, Perseu utilizou um escudo brilhante e através do reflexo, podia ver a Medusa sem olhá-la de frente. Quando ela se aproximou, Perseu usou a foice dada por Hermes e the cortou a cabeça.

Esse mito representa bem os medos e temores que vivemos quando temos que enfrentar situações que fogem ao nosso controle e queremos evitar a todo custo. Porém, inevitavelmente em algum momento, iremos encará-las frente a frente. Assim como Perseu que, mesmo sabendo dos poderes terríveis da Medusa, usou da inteligência para derrotá-la, em situações de crise temos que encontrar novas soluções para novos problemas e não adianta utilizar as velhas fórmulas porque as mesmas não vão funcionar. Usando a alegoria desse mito para fazer um paralelo com os desafios que enfrentamos no dia a dia da escola hoje, quantas vezes, nós educadores, achamos que a escola estaria incólume de qualquer mu- dança brusca? Quantas vezes achamos que ela passaria ilesa por qualquer onda de mudança vivida pela sociedade? Quantas vezes acreditamos que daríamos nossas aulas sempre da mesma forma, independente do que acontece no mundo lá fora? Tais atitudes são totalmente enganosas quanto à realidade que vivenciamos.

As mudanças ocorridas com o advento da informática e as novas formas de difusão da informação levaram por terra as bases que nos sustentaram por tanto tempo e que nos mantinham seguros. Assim como aqueles que tentaram matar a Medusa encarando-a de frente foram petrificados, nós educadores, por vezes, nos vemos petrificados pelo poder avassalador das Tecnologias da Informação e Comunicação. Um das primeiras reações que temos é a de ignorar o novo e tentar menosprezá-lo ou vê-lo como ameaça. Então buscamos apoio em nossas "velhas muletas" que garantiram nossa segurança durante todo o tempo. Lidar com o novo é um processo muito desafiador, pois induz a uma reformulação da ordem vigente. A filósofa Hanah Arendt, em $\boldsymbol{A}$ crise na $\boldsymbol{E}$ ducação - seu conhecido ensaio de 1958 - descreve bem esse sentimento de incerteza que os momentos de crise provocam em nós. Os momentos de crise nos oferecem a oportunidade de mergulhar na essência do problema. É quando nos deparamos com situações novas com as quais não estamos habituados e querer resolvêlas com soluções pré-concebidas não é a melhor alternativa: 
O desaparecimento dos pressupostos significa simplesmente que se perderam as respostas que vulgarmente se aceitam sem sequer nos apercebermos de que, na sua origem, essas respostas eram respostas a questões. Ora, a crise forçanos a regressar às próprias questões e exige de nós respostas, novas ou antigas, mas, em qualquer caso, respostas sob a forma de juízos diretos. Uma crise só se torna desastrosa quando lhe pretendemos responder com ideias feitas, quer dizer, com preconceitos. Atitude que não apenas agudiza a crise como faz perder a experiência da realidade e a oportunidade de reflexão que a crise proporciona (ARENDT, 1958, p. 2).

Pode-se presumir que toda situação de crise traz consigo uma situação de desconforto que nos força a mudar de alguma maneira. É o que acontece hoje em relação à profissão docente. Os saberes que possuímos parecem não dar conta dos contextos que vivenciamos no cotidiano escolar. O resultado é um sentimento de impotência e frustração que acaba levando o professor a adotar algumas posturas. Uma delas é simplesmente ignorar os fatos e seguir como se nada ocorresse, pois as coisas são assim mesmo e não adianta querer mudar os fatos. Outra postura é cair no conservadorismo, tentando a todo custo estabelecer uma autoridade baseada num saudosismo que não se sustenta mais. Situação que inevitavelmente acaba gerando conflitos muito desgastantes. Alguns procuram inovar, utilizando novas formas de lidar com essa nova geração. Procurando adaptar-se aos novos tempos, mas muitas vezes esses profissionais recebem pouco apoio, são desestimulados pelos colegas ou pelo próprio sistema. O que fica claro é que a escola na atualidade vive um momento crucial. Um momento no qual terá que se reinventar para poder continuar existindo. Ela não é mais detentora absoluta do conhecimento. Os avanços na informática permitiram uma difusão do conhecimento de uma maneira jamais vista e provocaram grandes mudanças nas noções temporais e espaciais. Elas afetam principalmente aquelas instituições que necessitam de alguma solidez para continuarem existindo. Para Arendt (1958), a escola é uma dessas instituições, pois ela e, consequentemente o professor - sua figura mais representativa - ancoram sua autoridade no passado. Os professores carregam a dupla função de conservar o mundo, transmitindo os conhecimentos historicamente aceitos e construídos, ao passo que também precisam inserir os "novos" nesse mundo. Essa relação é conflituosa porque o novo é sempre visto como ameaça, mas é em cada geração que chega que está a esperança de mudança que, segundo Arendt, impede que o mundo, assim como nós, torne-se perecível. Portanto, a tarefa do professor não é nada fácil. Ele tem a responsabilidade simultânea de proteger o mundo da criança e proteger a criança do mundo. Trouxemos essa questão a tona por acreditarmos que não é possível mergulhar na essência da crise que vivemos atualmente se não voltarmos nossos olhares ao sentido que a educação e a escola tiveram e têm para a sociedade moderna. Se ela foi concebida para ser uma representação, o "sacrário" do conhecimento legítimo produzido pelas gerações, fica mais fácil entender porque é tão difícil para a escola e para o professor assimilar inovações, mesmo que seja invariavelmente empurrado a elas pela necessidade que a sociedade tem de educar seus jovens. Tomando esta perspectiva, podemos afirmar que a profissão docente nunca estará isenta de tensão, pois encontra-se nos limites entre a conservação e a inovação.

Sendo assim, com o advento das tecnologias informacionais no ambiente escolar, surge a necessidade de se discutir a importância de uma nova modalidade de 
letramento além do alfabético: o letramento digital. Segundo Kleiman (1995) "podemos definir hoje o letramento como um conjunto de práticas sociais que usam a escrita enquanto sistema simbólico e enquanto tecnologia, em contextos específicos, para objetivos específicos" (p.19). Soares (2002) define letramento como "o estado ou condição de indivíduos ou de grupos sociais de sociedades letradas que exercem efetivamente as práticas sociais de leitura e de escrita e que participam competentemente de eventos de letramento" (p.145).

Já o letramento digital também é definido por Soares (2002)

como certo estado ou condição que adquirem os que se apropriam da nova tecnologia digital e exercem práticas de leitura e de escrita na tela, diferente do estado ou condição - do letramento - dos que exercem práticas de leitura e de escrita no papel (SOARES, 2002, p. 151).

A partir de tais definições, a pesquisa, em que se baseou este texto, procurou realizar uma discussão sobre a prática docente intermediada por tecnologias digitais, tendo com foco o letramento digital do professor. Entender a relação que o professor estabelece com as tecnologias de informação e comunicação é de fundamental importância para a elaboração de políticas de formação de professores mais orientadas com as demandas observadas em sala de aula, em especial aquelas voltadas para a inclusão digital não só dos alunos, mas também dos docentes.

Ao invés de abordar os impactos dos meios digitais no cotidiano dos alunos, o trabalho em questão procurou discutir essa questão sob a perspectiva do professor. Escolheu-se esse enfoque por considerarmos ser pertinente entender como o professor se relaciona com os meios digitais na sua prática, pois ao compreendermos a relação que o mesmo estabelece com as tecnologias na sala de aula, poderemos identificar quais aspectos didáticos e metodológicos envolvendo o uso desses recursos devem ser levados em conta no processo de formação do docente. Concordamos com Mello (2004) quando afirma que:

Ao colocar as tecnologias a serviço da melhoria da qualidade da formação do professor, essa abordagem metodológica também está preparando o professor para usar as novas tecnologias com seus alunos, em contextos nos quais essas tecnologias estejam disponíveis (MELLO, 2004, p. 139).

A pesquisa procurou captar a perspectiva do professor sobre seu letramento digital, descrevendo e interpretando as práticas digitais desenvolvidas por ele e seus desdobramentos percebidos na aprendizagem dos alunos. Utilizou-se da abordagem etnográfica de pesquisa para subsidiar o estudo de caso de um professor da Educação Básica - sujeito da pesquisa - no município de São Bento do Una - PE, numa escola que disponibiliza, para as atividades cotidianas, recursos digitais (lousas digitais, equipamentos diversos de informática, dentre outros).

\section{Abordagem MetodológicA}

A pesquisa desenvolvida pode ser caracterizada, do ponto de vista dessa abordagem, como uma pesquisa de caráter qualitativo; em relação aos objetivos como exploratória-descritiva e quanto aos procedimentos técnicos como um estudo de caso do tipo etnográfico. A justificativa para o enfoque metodológico aqui descrito se deve ao fato de concordarmos com Stake (2011) quando afirma que "a pes- 
quisa não é uma máquina que processa fatos. A máquina mais importante em qualquer pesquisa é o pesquisador. Ou uma equipe de seres humanos" (p.46). Além disso, deu-se ênfase a microanálise e a microinterpretação, entendidas aqui como uma atribuição de significado à experiência que um indivíduo pode viver, considerando os acontecimentos observados como únicos.

Nesta pesquisa, o interesse maior foi na observação de eventos, narrativas, situações e episódios envolvendo o sujeito em questão. $O$ procedimento de coleta de dados se deu através de questionários estruturados aplicados ao professor após cada sessão de observação participante para complementar o entendimento sobre as interações observadas na sala de aula. Utilizou-se também de entrevistas e análise de discurso do professor por meios relatos escritos. As observações participantes foram realizadas em sala de aula e no laboratório de informática pelo período de um ano, de 15 em 15 dias, por duas horas/aulas numa turma de $6^{\circ}$ ano. Os momentos de interação do professor com as mídias foram registrados por meio de fotografias, captação de áudio e filmagens. Feita a coleta de dados, os pesquisadores redigiam o relatório de campo que servia de suporte a triangulação com os questionários e entrevistas dadas pelo professor. Feitas as triangulações, os resultados eram interpretados e analisados à luz da literatura sobre o tema.

O estudo de caso do tipo etnográfico realizado nesta pesquisa utilizou por base algumas características baseadas em Lüdke e André (1986, p. 18) que visam à descoberta de novos conhecimentos sobre o tema, a ênfase na interpretação do contexto, o relato da realidade de forma completa e profunda e na variedade de fontes de informação.

\section{DISCUSSÃO DOS RESULTADOS}

A análise dos dados, a partir da triangulação, das observações, entrevistas e todo material analisado durante a pesquisa permitiu tecer algumas considerações sobre o letramento digital docente. A primeira delas revelou a tentativa do professor Paulo (sujeito da pesquisa) em incorporar o uso de mídias digitais em sua prática, porém limitando-a a função de recurso. Essa limitação ficava expressa no discurso do professor quando afirmava que os recursos digitais eram utilizados, de acordo com ele, para "prender ou chamar a atenção dos alunos" ou "expor os conteúdos". Consequentemente, a mídia era explorada como elemento ilustrativo daquilo que o professor considerava importante e necessário que seus alunos aprendessem.

Essa limitação corrobora a linha de pensamento defendida nesta pesquisa relacionada ao paradigma da transmissão e a necessidade de conservação que permeiam a função docente. Lembrando que a ideia de conservação aqui defendida não significa conservadorismo, mas é utilizada no sentido preservação. O discurso do professor Paulo reforça essa postura quando sua prática e metodologia são sempre norteadas pela necessidade de repassar aos alunos aquele conteúdo ou conceito que considera importante. Quando a necessidade de conservação se deparava com um contexto em que a aprendizagem se dava através das mídias digitais disponibilizadas pela escola, ocorria uma tensão que deixava o professor numa situação em que, além de se sentir responsável pela transmissão dos conhecimentos e sua conservação, sentia-se provocado a realizá-la com o suporte das mídias digitais. Dessa situação resultava um conflito metodológico decorrente da formação que o professor possuía e as habilidades exigidas dele para operar os recursos digitais. Essa perspectiva também foi percebida nas entrevistas feitas com o diretor da 


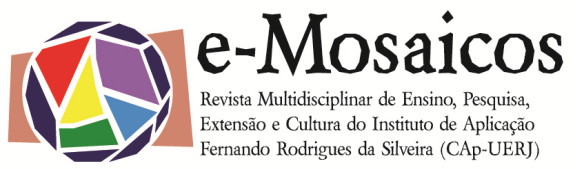

escola, quando relatou a resistência por parte dos professores quando se deparavam apenas com as lousas digitais na sala de aula.

Quando o professor se via forçado a aplicar sua metodologia num contexto de mídia digital sem a presença do "quadro negro", observamos duas situações distintas na escola. Primeiramente o aspecto positivo que se deu ao fato de que não houve rejeição ao uso dos recursos midiáticos na escola pelo professor Paulo que sempre tentou lançar mão deles na maioria das aulas observadas. Porém, ao mesmo tempo, percebia-se uma insegurança do professor em sua prática que deixava transparecer certo despreparo técnico e metodológico nos momentos de interação com as mídias digitais.

$\mathrm{Na}$ esteira dessa perspectiva, uma situação na qual o acesso aos recursos digitais suplantam os recursos ditos tradicionais, ficou mais claro o descompasso entre a formação recebida pelo professor e sua experiência cotidiana e as habilidades exigidas pela utilização das mídias digitais na escola. Essa contradição colocava o professor numa espécie de "limbo" onde, de um lado podia escolher não realizar nenhuma mudança em sua prática, por decisão pessoal ou porque era mais cômodo continuar fazendo o que sempre fez. E do outro, a presença do recurso digital na sala de aula o provocava a incorporar esse recurso, mesmo sem conhecer efetivamente suas aplicabilidades e possibilidades educativas. O professor Paulo assumia o risco da segunda opção. Em sua prática ficou nítida a dupla responsabilidade que se configura entre a ideia de conservação e a necessidade de inovação.

Ao assumir essa dupla responsabilidade, o professor Paulo invariavelmente buscava conciliá-las. E é justamente nessa busca pela conciliação que surge a necessidade do desenvolvimento do letramento digital do professor. Ele serviria de ponte entre esses dois lados aparentemente o- postos. Aparentemente porque cada inovação supõe uma reflexão invariável sobre o que ainda precisa ser conservado.

Negar as amplas possibilidades pedagógicas que as mídias digitais permitem, em especial a dois aspectos que afetam a função docente: a difusão de informação e a produção de conhecimento que se dão além dos limites da escrita no papel e do livro impresso, mídias muito comuns na prática docente seria um retrocesso. A transposição didática realizada através das mídias digitais exige do professor novas competências que interferem tanto na abordagem dos conteúdos como nas formas de linguagem utilizadas que irão impactar nas formas de aquisição da informação também por parte dos alunos e na construção do conhecimento que não se processa apenas na relação emissorreceptor tão comuns nas interações de sala de aula entre professor e aluno.

As mídias digitais permitem um acesso rápido e múltiplo a variadas informações, além de estimular os diversos sentidos humanos nesse processo. Esse processo poderá ter efeitos na forma como os alunos apreendem as informações e consequentemente a produção de conhecimentos.

Exemplificam essa situação as atividades observadas no laboratório de informática. Quando os alunos foram expostos ao jogo proposto pelo professor Paulo e foram perguntados posteriormente se preferiam realizar as operações matemáticas na tela do computador ou no papel, a maioria respondeu que preferia o papel. Alguns argumentaram que na tela do computador a preocupação maior não era pensar sobre a resposta do cálculo, mas respondê-lo o mais rápido possível para cumprir o objetivo do jogo e passar de nível. Neste caso ficou evidente que o uso da mídia se resumia a uma ação feita mecanicamente pelo aluno, desprovida de uma finalidade, de uma reflexão. O esforço do professor Paulo em fazer uso do 
laboratório é valido, mas sem uma orientação e objetivos bem definidos e alinhados com os recursos da mídia e suas possibilidades pedagógicas, acaba se perdendo a oportunidade de construir uma situação de aprendizagem realmente significativa para os alunos. Mas essa competência não se desenvolve tão rapidamente. Ela será resultado de um processo de reflexão, tentativa e erro desse professor sobre sua própria prática. Tão pouco o fará sozinho, pois precisa ser estimulado e incentivado pela escola. Essa situação só aumenta a responsabilidade dos cursos de formação de professores que deverão expor os futuros docentes ao contato com as mídias, num modelo de formação com e para as tecnologias. Para os professores em exercício, fica o registro importante do professor Paulo sobre a necessidade de formações continuadas nos espaços escolares voltadas para o uso de mídias na escola:

É fundamental! Nós tivemos uma capacitação só que foi uma capacitação de como você utiliza aqui na escola. Como você utilizar a lousa, como utilizar a caneta né! Como você colocar um pen drive, abrir certo! Só que pra você fazer isso aqui você tem que trazer de casa pronto e tem muita gente que não tinha essa noção de como pesquisar na internet, de como baixar um vídeo, qual programa utilizar. Os sites que procurar. Então foi fundamental o uso aqui. Só que ainda seria necessária uma aula, uma capacitação mesmo por área de disciplina pra melhor você ter um relacionamento [...] Eu acho que ainda nós somos analfabetos em termos disso ainda, certo? A gente busca todos os dias, tem uns que tem conhecimento a mais que outro e vai mexendo e vai aprendendo cada dia mais. Mas quanto mais capacitação melhor (Relatório de observação de campo, 2014).
Nesse depoimento do professor Paulo observa-se a necessidade de uma formação do professor para o uso de mídias, mas que não seja uma formação limitada à operacionalização do recurso. Uma formação mais ampla, direcionada. Mesmo que o professor Paulo não deixe explicito em seu discurso, pode-se presumir que esta formação deva contemplar metodologias de ensino aplicadas aos componentes curriculares. Portanto, deve ser orientada a um método.

Outro aspecto relevante do relato do professor Paulo se relaciona com a disponibilidade do professor em interagir com as mídias, comparado a uma criança quando ganha um brinquedo novo e tenta montá-lo e desmontá-lo. Existe o interesse do professor em utilizar as mídias digitais, de explorá-las. Essa curiosidade do professor serve de impulso, de estágio inicial para uma apropriação mais eficiente dessas mídias na educação.

Por fim, as mídias digitais podem ser grandes aliadas na construção de novos conhecimentos, mas a máquina não funciona sozinha. Quem orienta o funcionamento da máquina é o ser humano. $A$ consciência humana é quem regula os procedimentos operatórios do computador e não o contrário. O letramento digital do professor se dará efetivamente quando essa consciência do uso da máquina estiver incorporada no discurso e na prática docente, sem perder de vista a dimensão humana do processo de educar. A necessidade do letramento digital do professor se coloca como essencial porque só assim será possível o mesmo dialogar com a realidade e com as novas formas de difusão e construção de conhecimentos. Devemos ter com a informática a mesma desenvoltura que temos com os livros. É como aprender um novo idioma. O professor letrado digital seria aquele que manipula eficientemente as mídias, de forma consciente e orientada a algum objetivo educacional, sem perder de vista a dimen- 
são humana que o processo de ensinar envolve.

Se quisermos entender ou procurar soluções para as questões que afligem o cotidiano escolar é imprescindível entender as limitações que a escola apresenta no contexto atual, pois essas são variantes importantes que podem estar dificultando a inclusão de novas práticas metodológicas mais alinhadas com as demandas dos alunos atualmente.

Quanto maior as dificuldades enfrentadas por nossos professores, maior será o clima desânimo e desmotivação. Fato que pode colaborar para a falta de inovação e assim perderemos a possibilidade de explorar todo o potencial que as novas mídias podem oferecer ao ensino. A partir das limitações é que podemos observar com mais atenção questões que por vezes passaram despercebidas. Essas limitações que fazem o professor buscar novos caminhos para a aprendizagem dos seus alunos, ou, por outro lado, acomodar-se. Se conseguirmos entender como o professor lida com as situações limitantes do seu contexto escolar e como o mesmo se apropria das mídias para fazer seu trabalho, podemos pensar numa formação docente mais consistente, fortalecendo o papel da escola e do professor.

Chegou o momento de voltarmos nossos olhares para a prática do professor. Desvelar suas contradições, entender os discursos e visões de mundo desse profissional. Compreender a formação de sua identidade, o caráter das relações que estabelece com seus alunos e sua condição de letrado digital.

A sala de aula é o laboratório que todo pesquisador na área de educação deve frequentar. A academia pode ajudar a escola e o professor a redefinir sua razão de existência num mundo onde $a$ informação é acessível tão facilmente. A pesquisa realizada no ambiente escolar tende a colaborar com o aprofundamento das questões que tanto afligem os educadores e conduzir a respostas condizentes com as dificuldades que enfrentam. Esse olhar é fundamental para superarmos o senso comum e que o professor possa ser o protagonista de sua prática de forma crítica e que se torne consciente do papel que deve ocupar na sociedade do conhecimento.

\section{CONSIDERAÇÕES FINAIS}

Espera-se que a pesquisa aqui descrita e seus resultados possam trazer contribuições relevantes para a discussão sobre formação docente e enriquecer as discussões sobre uma formação docente orientada para o letramento digital. Os fragmentos da pesquisa contribuem para o entendimento sobre os modos como a escola e seus sujeitos compreendem o uso das mídias digitais em sala de aula.

Há que se destacar que, em alguns momentos da pesquisa, o diretor da escola, João, descreveu que, invariavelmente, ele percebia o caráter conservador presente na prática dos professores no uso dos recursos tecnológicos disponíveis na escola. Este fato reforça a concepção de que a inovação na prática docente ocorre de forma processual e lenta e é perceptível no trecho a seguir onde ele relata a dificuldade dos professores da escola em se adaptar as lousas digitais que foram instaladas em todas as salas de aula da escola:

Foi radical no início porque a escola só ofereceu essa opção. Não existia outra. Hoje a gente já tem por que a gente viu que tinha uma hora que se a tecnologia falhasse a gente precisava (...) e a gente viu também que tinha, principalmente no primário, alunos com faixas etárias diferentes que precisavam de uma atenção em separado. Então a gente colocou quadros brancos, mas esse professor hoje não gosta de utilizar esses quadros. Só usa mais 
no primário (Relatório das observações do campo, 2014).

Algumas questões também foram evidenciadas: a escola, ao substituir o quadro branco pela lousa digital criou uma situação onde o professor viu-se forçado a abandonar práticas de letramento comuns na escola. Esta situação é interessante pelo fato de, intencionalmente ou não, forçar o professor a se aventurar em novas possibilidades de escrita e utilização de linguagens que ele não está habituado a fazer, mas por outro lado, gera insegurança que se dá em dois níveis: tanto no aspecto metodológico do professor como no aspecto técnico do uso da máquina que quando falha impossibilita a realização do trabalho ao ponto da escola ter que instalar novamente quadros brancos. Outro aspecto relevante se deve ao fato de que esta situação foi mais evidenciada no primário, talvez pelo fato de que nessa modalidade de ensino a criança precisa desenvolver de forma mais efetiva o letramento alfabético, onde ainda o professor acredita ser mais difícil desenvolver a escrita numa plataforma digital.

Ainda sobre as impressões de João sobre o letramento digital de seus professores, há um tom sutil de otimismo em sua fala quando afirma que o professor não rejeita o uso da tecnologia em sua prática, porém, quando perguntado sobre o que entende por inovação pedagógica com o uso de mídias, suas afirmações induzem a pensar que existe uma lacuna entre o uso que o professor faz dos recursos digitais e suas reais possibilidades pedagógicas:

Aí esse professor, ele foi como se fosse aprendendo. Ele não usa a tecnologia como diz assim... de maneira desejada. Às vezes pega um texto e bota lá para o menino copiar. Existe isso ainda (Relatório das observações do campo, 2014).
Pode-se destacar uma questão sobre o letramento digital docente nesta afirmação. É possível pensar numa formação docente na qual a alfabetização tecnológica do professor seja necessária, mas que essa alfabetização tecnológica não seja dissociada de uma atualização metodológica onde o professor, ao ter contato com as mídias em sua prática, ao mesmo tempo em que aprende a manuseá-la, repensa sua prática pedagógica.

A transposição do letramento alfabético para o digital força o professor a construir novas abordagens dos conteúdos, visto que, devido às diversas possibilidades permitidas pelos meios midiáticos digitais transpõem de longe as limitações do texto escrito. Essa discrepância gera uma insegurança que culmina numa situação em que o professor acaba repetindo procedimentos pedagógicos comuns ao letramento da escrita no papel numa plataforma digital. A questão importante é se esta transposição é uma fase necessária a incorporação paulatina da mídia pelo professor até um estágio mais eficiente do uso da mídia ou uma rejeição inconsciente desta. O que faz um professor colocar um texto num editor na tela do computador e pedir para que o aluno o transcreva em seu caderno? Para fazer isso não necessitaria do recurso midiático. Até que ponto esse comportamento resulta de uma postura política do professor ou reflete as limitações de sua formação didática? Mais a frente esta questão será retomada quando for descrita a ação do professor em sala de aula. O que fica evidente é que, não concepção da gestão, o professor não faz o uso eficiente das mídias porque está num estágio em que a ainda está aprendendo a lidar com ela e para tanto se utiliza de procedimentos que já conhece e com os quais se sente seguro e os acaba repetindo quando utiliza os recursos digitais. 
O professor reconhece a importância de inovar e de utilizar as mídias em sala de aula, mas como utilizá-la e transpor sua função de recurso é um desafio muito maior que, como nessa pesquisa, exigirá de Paulo uma reflexão e análise profunda de sua prática, algo que não se faz de um dia para o outro. O que foi constatado é que existe uma limitação metodológica por parte do professor em explorar os recursos midiáticos. No caso do professor Paulo existe uma tentativa de aceitação e utilização da mídia, mas falta uma consciência do seu potencial para construir novas possibilidades de aprendizagem nos alunos. Uma consciência do caráter metodológico e técnico poderia contribuir para a prática de Paulo, bem como promover um uso das mídias mais eficiente com seus alunos.

\section{REFERÊNCIAS BIBLIOGRÁFICAS:}

ARENDT, Hanah. A crise na Educação. 1958. Disponível em: redeantiga.unifeire.org. Acesso em 06 de novembro de 2012.

COSCARELLI, Carla; RIBEIRO, Ana Elisa (org.). Letramento Digital: aspectos sociais e possibilidades pedagógicas. 3. ed. Belo Horizonte: Autêntica, 2011.

KLEIMAN, A. (Org.). Os significados do letramento: uma nova perspectiva sobre a prática social da escrita.Campinas: Mercado de Letras, 1995, p. 15-61.

LÜDKE, M; ANDRÉ, Marli E.D.A de. Pesquisa em educação: abordagens qualitativas. São Paulo: E.P.U, 1986.

MELLO, Guiomar Namo de. Educação escolar brasileira: o que trouxemos do século XXI? Porto Alegre. Artmed, 2004.

SILVA, Wellington de Brito. Letramento digital e prática docente: um estudo de caso do tipo etnográfico em uma escola pública. 2014. 95p. Dissertação (Mestrado Profissional em Educação) PPGFPUniversidade Estadual da Paraíba.

SOARES, Magda. Novas práticas de leitura e escrita: Letramento na cibercultura. Educação e Sociedade. Campinas, vol. 23, no 81, p. 143, 160. 2002.

STAKE, Robert E. Pesquisa qualitativa: estudando como as coisas funcionam. Porto Alegre: Penso, 2011. 